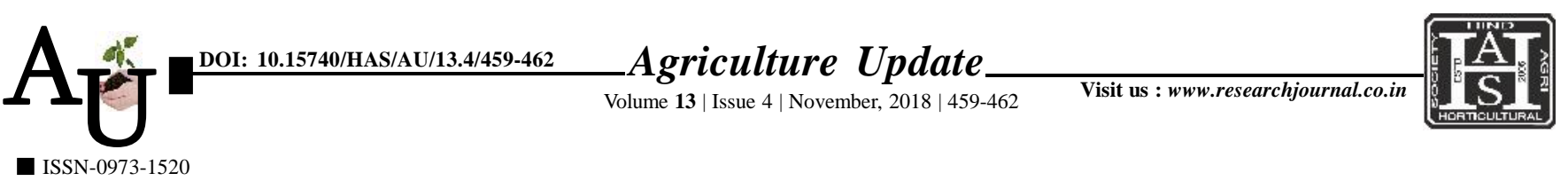

\title{
Research Article: Agri-preneurship development through gerbera cultivation
}

Jayprakash H. Gaikwad

Article Chronicle:

Received :

13.08.2018;

Revised :

03.10.2018;

Accepted :

20.10.2018

KEY Words:

Agri-preneurship, Gerbera cultivation

Author for correspondence :

\section{Jaypraksh H.}

Gaikwad

Department of

Agricultural Extension,

Agriculture Technology

School, Puntamba,

Ahmednagar (M.S.) India

Email:jh_gaikwad@

rediffmail.com Agri-Horticultural Society.
SUMMARY : Maharashtra is a significant producer and global exporter of gerbera and rose. It is the largest producer of gerbera in the country. It has accomplished this horticulture success and exports in 2009, with just 12.00 per cent of its cultivated land dedicated to floriculture. Hundreds of families engaged in cultivation of gerbera in Maharashtra. The entrepreneurial behaviour is not necessarily doing new things but also doing things in a new way that has been already done. The entrepreneur is an economic man who strives to maximize his profits by adoption of innovations. However, entrepreneurs are not simply innovators, they are mean with a will to act, to resume risk and to bring changes through organization of human efforts (Dannof, 1949). Now it is felt that, the economic growth and development of advanced countries is largely increased due to entrepreneurship among their community rather than to capital. However, entrepreneurs are not simply innovators, they are mean with a will to act, to resume risk and to bring changes through organization of human efforts (Dannof, 1949). Now it is felt that, the economic growth and development of advanced countries is largely increased due to entrepreneurship among their community rather than to capital. The specific objectives of the study were to study the entrepreneurial behaviour of gerbera growers. The present study was conducted in Ahmednagar District of Maharashtra state. Ahmednagar district was purposively selected as it has the maximum area under gerbera cultivation and ranks first in production. The data was collected by interviewing 120 gerbera growers with well-designed and pre-tested schedules. Later simple mean, percentage, standard deviation and correlation co-efficient were used to know the relationship between selected independent and dependent variables. The study revealed that majority of the gerbera growers had medium level of entrepreneurial behaviour, followed by low and high level of entrepreneurial behaviour. This might be because of their medium level of innovativeness, achievement motivation, decision making ability, economic motivation, leadership ability and management orientation.

How to cite this article : Gaikwad, Jayprakash H. (2018). Agri-preneurship development through gerbera cultivation. Agric. Update, 13(4): 459-462; DOI : 10.15740/HAS/AU/13.4/459-462. Copyright@ 2018: Hind 